\title{
Predicting compliance with annual follow-up evaluations in persons with spinal cord injury
}

\author{
Kay C Canupp ${ }^{1}$, Ken B Waites ${ }^{1-3}$, Michael J DeVivo ${ }^{1}$ and J Scott Richards ${ }^{1}$ \\ The Departments of ${ }^{1}$ Rehabilitation Medicine, ${ }^{2}$ Pathology and ${ }^{3}$ Microbiology, University of Alabama at Birmingham, \\ Birmingham, AL, USA
}

\begin{abstract}
A prospective study was performed to determine why some persons with spinal cord injury (SCI) fail to return for scheduled evaluations in order to identify predictive factors that could be used to target those at greatest risk for noncompliance and facilitate interventions to improve rates of return. Sixty-one noncompliant subjects and 102 persons compliant with regularly scheduled annual examinations were paid to come to the clinic for evaluation. Each participant completed a psychological questionnaire comprised of theoretical and socioeconomic variables. There was no difference between the two groups according to gender, race, level or completeness of injury, education, etiology of injury, responses to questions from the Health Locus of Control Scale, Health Beliefs Model, inconvenience or discomfort. For noncompliant versus compliant persons, cost $(P=0.0002)$, distance $(P=0.0047)$, transportation $(P=0.0330)$, belief that follow-up was not necessary $(P<0.0001)$, availability of good local doctor $(P=0.0001)$ and time $(P=0.0209)$ were identified as obstacles to returning for followup. These data indicate a need to improve the education for newly injured persons as well as those persons residing in the community on the importance of regular urological follow-up, to maintain close contact post-discharge and to assist in identifying community resources to facilitate either compliance with planned evaluations or the development of acceptable alternatives.
\end{abstract}

Keywords: spinal cord injury; compliance; urological complications

\section{Introduction}

Spinal cord injury (SCI) affects over 200,000 persons in the United States with an estimated 10,000 new cases occurring each year. ${ }^{1-3}$ One of the most devastating conditions known to man, its severity, consequences, and costs have made SCI a major national public health concern. Renal failure, once among the most common causes of death in persons with SCI has declined somewhat in importance during the past several years as a result of improved acute care, early identification of problems and the treatment of urological complications through organized SCI care centers. Even though mortality due to renal dysfunction secondary to chronic or recurrent urinary tract infections has decreased, long-term surveillance of the urinary tract is mandatory for the optimum management of persons with SCI to preserve their overall health and minimize secondary complications. Urinary tract abnormalities may occur up to many years following injury and, due to the sensory deficit, may go undetected for long periods unless periodic urinary tract examinations are performed. Urological complications associated with chronic or recurrent urinary tract infection and other secondary disabilities such as

Correspondence: Ken B Waites pressure ulcers in persons with SCI are now thought to be preventable or can at least be reduced in number and/or severity providing those at risk maintain appropriate personal care practices and adhere to prescribed regimens. ${ }^{4,5}$ While there is general agreement that periodic evaluation of the urinary tract is indicated following SCI, neither the optimum timing or the frequency of examinations nor their methodology has been universally agreed upon. In general, our practice has been to evaluate persons annually beginning one year post-injury for the presence of urological abnormalities.

Although a comprehensive database on patients followed annually after completion of the initial phase of rehabilitation is maintained at our SCI center, our patient population, much like that in other centers, has a high rate of noncompliance with recommended follow-up evaluation, exceeding $50 \%$ by 10 years post-injury. Few prospective investigations have been performed in persons with SCI to determine the reasons for noncompliance with scheduled follow-up evaluations.

To address this question, we compared compliant persons with noncompliant persons to evaluate demographic, psychological and socioeconomic variables to establish whether there were predictive factors 
which could be used to target those at greatest risk of noncompliance with scheduled annual urologic evaluations. The goal of this investigation was to identify reasons for noncompliance so that appropriate interventions could be developed to improve rates of return. The project was performed with the approval of the Institutional Review Board and written informed consent was obtained from all participants.

\section{Patients and methods}

\section{Study population}

The study population consisted of adults identified through our computerized SCI database who received inpatient rehabilitation services at our institution for traumatic SCI sustained between the years 1977 and 1986. To be enrolled in this database, a person must have been injured in Alabama and must have resided in Alabama at the time of injury. All demographic groups were eligible, and there were no restrictions regarding neurological levels or grades of injury.

Unrelated additional study admission requirements were that a renal scintillation $\operatorname{scan}^{6}$ had been performed during the initial hospitalization or within 1 year post-injury for which valid results were available and that all persons had two kidneys. These criteria were necessary for other aspects of the study concerning long-term renal function following SCI that have been reported separately, and should have no effect on the results reported here.

Noncompliant subjects identified from the SCI database were those who had missed at least the two most recently scheduled annual urological examinations and who were completely lost to follow-up, either by refusal to return for evaluation or by relocation without providing a forwarding address. Persons meeting the above entry requirements who were compliant with annual examinations since injury, had kept the last two scheduled clinic appointments and who had a current address and telephone number on file were studied for comparison.

\section{Patient selection and enrollment}

Noncompliant subjects identified from the SCI database were sought by telephoning the last known number available in our records, telephoning relatives to find out new addresses and telephone numbers, and by mailing letters to the last known address. Using these procedures, it was possible to locate 80 noncompliant persons, previously lost to follow-up. Sixty-one of these people returned for a comprehensive examination when requested to do so for the purposes of this prospective study. There was no significant difference among those who refused to participate and those who agreed to be subjects with respect to age at injury, years post-injury, race, gender, level of injury, completeness of injury or educational level achieved. Compliant persons, as defined above, were contacted a few weeks prior to their next scheduled annual examination and asked to take part in this prospective study. A total of 102 individuals, contacted sequentially according to their next scheduled clinic appointment agreed to do so. There were no refusals among this group of patients.

Both compliant and noncompliant participants in the study received $\$ 100$, two free meals, and conveniently located free parking for undergoing a comprehensive urological examination and completing psychological questionnaires designed to identify reasons for noncompliance. Written informed consent was obtained from all participants.

\section{Data collection}

Demographic data and detailed injury information were collected at the time of the injury. Follow-up information on the urological status was collected at the annual evaluation.

For the purposes of this study, in addition to the urological examination and health status information that is routinely collected at the annual evaluations, a detailed questionnaire was administered to subjects and controls. This questionnaire consisted of The Health Locus of Control Scale, ${ }^{7}$ The Health Beliefs Model $^{8}$ and 18 other questions that were related to the study objectives dealing with items such as income, frequency of urinary tract infections, history of urological complications, third party sponsorship, other sources of health care, relationship with clinic psychiatrists, specific reasons for non-return and distance from the patient's home to the SCI clinic.

The version of the Health Locus of Control Scale ${ }^{7}$ used in this study included a series of 11 items graded on a scale of 1 to 6 designed to yield a single score by summing the individual responses to each question. The higher the overall score, the more external the belief in locus of control, ie, health is determined by factors over which individuals have little control such as luck, fate or chance. On the other hand, persons who have an internal locus of control believe that one becomes healthy or sick as a result of his or her own behavior. Our hypothesis was that persons with SCI who score high on the internal pole of the scale perceive a link between their own behavior and subsequent health and are more likely to comply with recommended annual evaluations than those who attribute health largely to matters of chance or other factors outside their control. Even though this construct has spawned a large number of publications which support its predictive value, no previous studies have been performed in persons with SCI to assess compliance with long-term follow-up examinations.

The Health Beliefs Model questionnaire ${ }^{8}$ consisted of 13 items graded on a scale of 1 to 6 . These questions were designed to ascertain whether there was a link between compliance with follow-up and the individual's perception of risk and vulnerability with regard to urological complications. This instrument 
has been tested prospectively and shown to provide a helpful framework for interpreting the phenomenon of noncompliance with long-run therapies. ${ }^{9}$

\section{Statistical analysis}

For interval level predictor variables such as age, means and standard deviations were calculated for cases and controls and compared by Student's $t$ test. All Health Locus of Control and Health Beliefs Model questions were considered to be interval rather than ordinal level measures so that more powerful parametric statistical tests could be used. Treating these items as interval level measures is the usual and customary mode of analysis and should not meaningfully distort the results while facilitating presentation and clarity of findings. For categorical predictor variables, percentages of each category for cases and controls were calculated and compared by the Pearson chi-square test. Yates' corrected chi-square test was used for intergroup comparisons, such as gender differences between cases and controls, that involved only two categories.

Given the number of persons evaluated in each group, statistical power to detect a difference of $25 \%$ between noncompliant versus compliant persons at a two-tailed alpha level of 0.05 is $90 \%$, while power to detect a smaller difference of only $20 \%$ between groups is reduced to $72 \%$. Moreover, power to detect a difference of 0.5 points in mean response between the two groups on items such as the Health Beliefs Model questions where standard deviations were usually approximately one point is $87 \%$ at a two-tailed alpha level of 0.05 . Since smaller differences than this are probably not meaningful, power is adequate for this study.

\section{Results}

A total of 61 subjects who had not been examined for a period between 3 and 15 years and 102 controls were studied. Demographic and injury-related characteristics of subjects and controls were not significantly different (Table 1). However, controls had completed roughly twice as many annual examinations for which they were eligible as subjects (87vs $44 \%$, respectively).

The reasons for not returning for follow-up urological evaluations among subjects and controls are summarized in Table 2. Both groups were asked to identify obstacles to returning for follow-up. Cost of the visit and medical tests, distance to travel, availability of transportation, belief that follow-up was not necessary and availability of good local doctors were identified as the major obstacles to returning to the clinic for follow-up by a significantly greater percentage of subjects than controls. There was no difference between the groups related to inconvenience of returning for follow-up. However, the time necessary for the clinic visit and discomfort associated with procedures conducted as part of the annual evaluation were identified as major obstacles to overcome by a significantly greater percentage of controls than subjects.

Among those participants who lived greater than 100 miles from the SCI clinic, there was no statistically significant difference in the percentage of subjects $(52 \%)$ and controls $(40 \%)$ who stated that distance was an obstacle $(P>0.05)$. Likewise, among persons who lived less than 100 miles from the SCI clinic, there was also no statistically significant difference in the percentage of subjects $(19 \%)$ and controls $(6 \%)$ who stated that distance was an obstacle to overcome $(P>0.05)$.

Among the subjects, 16 of $61(26 \%)$ reported that they had a primary care physician. However, only three subjects $(5 \%)$ admitted to undergoing regular preventive care visits. Even though 20 subjects (33\%) were able to identify a urologist by name, none had regular urological examinations.

Table 1 Characteristics of subjects and controls

\begin{tabular}{|c|c|c|c|}
\hline Variable & $\begin{array}{l}\text { Subjects } \\
(\mathrm{n}=61)\end{array}$ & $\begin{array}{l}\text { Controls } \\
(\mathrm{n}=102)\end{array}$ & $\mathrm{P}$ value \\
\hline $\begin{array}{l}\text { Annual examina- } \\
\text { tions completed }(\%)\end{array}$ & 44 & 87 & \\
\hline \multicolumn{4}{|l|}{ Years of age } \\
\hline range & $14-48$ & $9-71$ & \\
\hline mean & 26 & 28 & 0.3886 \\
\hline \multicolumn{4}{|l|}{ Years post injury } \\
\hline range & $7-17$ & $6-17$ & \\
\hline mean & 12 & 11 & 0.8429 \\
\hline Males $(\%)$ & 80 & 89 & 0.2555 \\
\hline White race $(\%)$ & 66 & 62 & 0.6464 \\
\hline Tetraplegia (\%) & 36 & 44 & 0.5241 \\
\hline Complete lesion $(\%)$ & 64 & 76 & 0.2270 \\
\hline Education attained (\%) & & & 0.2201 \\
\hline Grade 8 & 18 & 17 & \\
\hline Grades 9-11 & 26 & 27 & \\
\hline High School & 54 & 46 & \\
\hline College Degree & 2 & 10 & \\
\hline Etiology of injury $(\%)$ & & & 0.1974 \\
\hline Motor vehicle crash & 56 & 55 & \\
\hline Violence & 31 & 22 & \\
\hline Sports & 7 & 9 & \\
\hline Falls & 7 & 11 & \\
\hline Falling object & 0 & 7 & \\
\hline Married (\%) & 30 & 29 & 0.9896 \\
\hline \multicolumn{4}{|l|}{ Rehospitalization during } \\
\hline previous year $(\%)$ & 23 & 27 & 0.6162 \\
\hline Employed (\%) & 20 & 26 & 0.3952 \\
\hline Sponsorship (\%)* & 44 & 43 & 0.8885 \\
\hline Annual Household & & & 0.3847 \\
\hline \multicolumn{4}{|l|}{ Income $(\%)$} \\
\hline$<\$ 5000$ & 14 & 23 & \\
\hline$\$ 5000-10,000$ & 37 & 28 & \\
\hline$\$ 10,000-20,000$ & 24 & 23 & \\
\hline$>\$ 20,000$ & 25 & 26 & \\
\hline
\end{tabular}

*represents percentage with private insurance, Workers Compensation or Department of Vocational Rehabilitation sponsorship which usually cover costs of annual examinations 
There were no significant differences between compliant and noncompliant persons with regard to mean responses for the Health Locus of Control Scale, individual responses to the Health Beliefs Model items or to specific questions developed for this population. Scores on the Health Locus of Control Scale were very consistent with norms reported in Wallston's original description, ${ }^{7}$ with participants tending somewhat towards more internal than external orientation (Table $3)$. For the Healths Beliefs Model questions, participants tended to utilize the extreme ends of the scale (strongly agree or disagree) indicating definitive beliefs about their health status and their ability to influence it.

Table 2 Reasons for not returning for scheduled urologic evaluations following spinal cord injury

\begin{tabular}{lccc}
\hline Variable & $\begin{array}{c}\text { Subjects } \\
(\mathrm{n}=61) \\
(\%)\end{array}$ & $\begin{array}{c}\text { Controls } \\
(\mathrm{n}=102) \\
(\%)\end{array}$ & P value \\
\hline $\begin{array}{l}\text { Cost of examination } \\
\text { Distance to travel }\end{array}$ & 44 & 18 & 0.0002 \\
$\begin{array}{l}\text { Availability of trans- } \\
\text { portation }\end{array}$ & 30 & 12 & 0.0047 \\
$\begin{array}{l}\text { Belief that follow-up } \\
\text { not necessary }\end{array}$ & 25 & 12 & 0.0330 \\
$\begin{array}{l}\text { Time involved } \\
\begin{array}{l}\text { Discomfort } \\
\text { Availability of good }\end{array}\end{array}$ & 10 & 0 & 0.0001 \\
$\quad \begin{array}{l}\text { local doctor } \\
\text { Inconvenience }\end{array}$ & 16 & 25 & 0.0209 \\
\hline & 13 & 18 & 0.0449 \\
& & 16 & 0.0001 \\
\end{tabular}

\section{Discussion}

Although there have been a number of studies on compliance with medical regimens in general, a literature review yielded no previous studies on compliance with long-term follow-up care for individuals with SCI. Obtaining compliance with recommended medical regimens in chronic disease states such as SCI is more problematic than for acute illness. ${ }^{10}$ The basic approach to compliance in chronic disease has been through the use of education and appeals to reason: informing patients about their disease and its long-term complications, laying out a plan of management including follow-up visits, and appealing through logic and reason for compliance. While there have been some documented successful attempts, ${ }^{10-12}$ the overwhelming picture in the chronic disease literature is one of increasingly poor compliance over time, a fact which is also reflected in our experience with persons who have SCI. Even though compliance can sometimes be impacted by a variety of different interventions, they typically have short-lasting benefit. ${ }^{12}$ One of the inherent difficulties with encouraging persons with SCI to take the time and expense to come back for annual examinations is that they may be asymptomatic and tend to negate the possibility that 'silent' complications may be developing, a perception which is common for many chronic disease states.

Numerous variables have been studied to determine correlates of medical compliance. For many of these variables, the number of studies which find a positive or negative association with compliance about equal

Table 3 Mean response to health locus of control, health beliefs and other questions

\begin{tabular}{|c|c|c|}
\hline & $\begin{array}{l}\text { Subjects } \\
(\mathrm{n}=61)\end{array}$ & $\begin{array}{l}\text { Controls } \\
(\mathrm{n}=102)\end{array}$ \\
\hline Health locus of control scale & 35.2 & 34.8 \\
\hline \multicolumn{3}{|l|}{ Health beliefs items } \\
\hline I will experience irreversible kidney damage in the next year & $1.2 *$ & 1.2 \\
\hline I will experience irreversible kidney damage in the next 5 years & 1.4 & 1.3 \\
\hline I already have irreversible kidney damage & 2.0 & 2.0 \\
\hline I view kidney damage as potentially life threatening & 5.4 & 5.4 \\
\hline If kidney damage occurs, it will require continued attention & 5.7 & 5.5 \\
\hline $\begin{array}{l}\text { When a doctor presribes medicine for me, I stop taking it when I feel better, even if there is } \\
\text { some left }\end{array}$ & 2.1 & 2.2 \\
\hline There is little I can do to prevent kidney problems from occurring & 1.7 & 1.6 \\
\hline Kidney damage is a serious medical problem that always requires a doctor's attention & 5.7 & 5.5 \\
\hline Patients with kidney damage never recover completely & 4.3 & 4.1 \\
\hline Kidney damage would have a major impact on my life & 5.6 & 5.6 \\
\hline Checkups often detect problems a patient isn't aware of & 5.8 & 5.5 \\
\hline The sooner a medical problem is detected, the better the chance for complete recovery & 5.9 & 5.8 \\
\hline When I've come for a checkup, it has caused no disruption in my routine & 3.1 & 3.1 \\
\hline I rarely have to spend time waiting to see someone when I come for a checkup & 4.0 & 3.7 \\
\hline I feel the doctors treat me with respect & 6.0 & 5.8 \\
\hline I feel comfortable enough with my doctor to discuss any problems I might be having & 5.9 & 5.9 \\
\hline I am very confident in my doctor's ability to diagnose any problems & 5.9 & 5.9 \\
\hline I am in excellent health & 4.7 & 5.0 \\
\hline
\end{tabular}

$* 1=$ strongly disagree, $6=$ strongly agree 
those which find no such relationship. Demographic and socioeconomic variables such as age, level of education, socioeconomic status, occupational status and race are as likely to be positively as negatively correlated. Our findings did not support any linkage in persons with SCI between such variables and the likelihood of complying with recommended follow-up examinations.

The influence of family and friends and family stability have been positively correlated with compliance. ${ }^{13}$ Feeling better or well, ${ }^{14}$ lack of transportation, ${ }^{15}$ and employment limitations ${ }^{16}$ also have been cited as excuses for noncompliance. Our data showed that lack of transportation was identified as a major obstacle to returning for follow-up by noncompliant persons as opposed to compliant controls. Our investigations did not specifically include evaluation of the family unit except for the determination of marital status which was not different between subjects and controls.

Our evaluation determined that compliant persons were significantly more likely than noncompliant persons to be concerned about the time involved for follow-up examinations and the potential discomfort from diagnostic procedures. These variables are perhaps more significant for those who routinely return because they are more keenly aware of these factors than the subjects who are less familiar with what actually takes place during the examination.

Only three of $61(5 \%)$ subjects reported that they underwent regular preventive medical examinations and none were seeing a urologist on a regular basis, confirming our intitial suspicions that most individuals who do not return for SCI clinic visits do not receive any type of preventive care through other facilities, possibly placing them at greater risk for clinically silent secondary complications which may escalate over time.

One of the better known predictive models of human behavior is the Health Beliefs Model which has had a number of modifications and enough empirical support for its validity to survive over the years. ${ }^{8}$ Proponents of this theory suggest that in order to influence health behavior, one must create a motive to avoid the perception of danger by presenting a clear image of threat with words and pictures, develop a case for a link between health behavior and the danger, and personalize the danger to increase the individual's perception of risk and vulnerability. Individuals must also believe in their ability to behave in such a way as to reduce such threats. The extent to which persons with SCI feel a sense of vulnerability about their bodies once rehabilitation is completed is unclear. Responses on the items relating to urologic complications derived from the Health Beliefs Model tended to fall in the extreme end of the scales (strongly agree or strongly disagree). This indicates that our sample as a whole espoused awareness of the seriousness of urologic complications, of the need for regular checkups and the belief that checkups can play an important active role in the prevention of urological complications. However, they also tended to believe that they themselves were unlikely to experience irreversible renal damage either in the year after completing the questionnaire or the following five years. Rodriguez and Garber ${ }^{17}$ found a similar trend in an outpatient survey of persons with SCI concerning the probability of developing a pressure ulcer. Although all of their sample had previously experienced a pressure ulcer, $82 \%$ believed they would not incur another ulcer during the next year. If this is a general belief among the SCI population post discharge, the need for continuous long-term patient education about the potential for renal damage and other complications is justified. Knowledge of the seriousness of urological and other complications does not appear to be the problem. Rather, getting persons with SCI to believe that they are at risk themselves and can do something to reduce that risk appears to be the problem.

Our population as a whole did not differ in responses to the Health Locus of Control Scale from norms published by Wallston et al. ${ }^{7}$ for their original derivation and fell somewhat below the mid-range of the scale indicating a trend toward internality, but not to any extreme. In fact, when our sample was divided into thirds based on the range of scores possible with the Health Locus of Control Scale (11-66), again, the vast bulk of our patients fell in the middle third with sample sizes in the extreme thirds too small for any meaningful statistical comparisons. Compliant persons versus noncompliant persons, most importantly, did not differ on this measure indicating that this particular scale was not helpful in determining who might or might not be likely to return for follow-up visits. There have been subsequent elaborations of the Health Locus of Control Scale, ${ }^{18}$ which could have been utilized in the study, but given our results, it is doubtful that other versions would have more discriminative ability.

Compliance is an individual issue that has to do with the person's positive views of his or her relationship with health care providers. Compliance will be enhanced if patients feel they are getting something in return for their efforts. Merely being told that they are healthy is not likely to be adequately compelling to ensure long-term compliance with annual examinations in persons who are permanently disabled due to SCI. Our findings indicate a need to improve educational efforts for new SCI patients, and perhaps more importantly, those residing in the community, on the importance of regular urological follow-up, to maintain close contact post-discharge, and to assist them in identifying resources within their communities to facilitate compliance with planned urologic evaluations or develop acceptable alternatives. Whether persons with SCI who are noncompliant with regular urological follow-up evaluations experienced more frequent or severe urological complications was the focus of a separate report. ${ }^{19}$ 


\section{Acknowledgements}

This work was supported by The Centers for Disease Control and Prevention Cooperative Agreement No. R49CCR406294, The National Institute on Disability and Rehabilitation Research Medical Rehabilitation Research and Training Center in Secondary Complications in Spinal Cord Injury Grant No. H133B800012 and the UAB Spinal Cord Injury Care System and National Spinal Cord Injury Statistical Center Grant No. H133N00001.

\section{References}

1 DeVivo MJ, Fine PR, Maetz HM, Stover SL. Prevalence of SCI a reestimation employing life table techniques. Arch Neurol 1980; 37: $707-708$

2 Ergas Z. SCI in the United States: a statistical update. Central Nervous Systsem Trauma 1985; 2: 19-29.

3 Feller BA. Prevalence of selected impairments United States 1977. Vital and Health Statistics 1981; Series 10, No. 134, DDS Publication (PHS) 81-1562.

4 Yarkony GM. Pressure ulcers: a review. Arch Phys Med Rehabil 1994; 75: $908-917$

5 Waites KB, Canupp KC, DeVivo MJ. Epidemiology and risk factors for urinary tract infections following spinal cord injury. Arch Phys Med Rehabil 1993; 74: 691-695.

6 Lloyd LK. New trends in urologic management of spinal cord patients. Central Nervous System Trauma 1986; 3: 3-12.

7 Wallston BA, Wallston KA, Kaplan GD, Maides SA. Development and validation of the health locus of control (HLC) scale. $J$. Consulting \& Clinical Psychology 1976; 44: 580-585.
8 Becker MH. Sociobehavioral determinants of compliance. In: Sackett OL, Haynes RB (eds.), Compliance with Therapeutic Regimens. John Hopkins University Press, Baltimore, 1976.

9 Maiman LA et al. Scales for measuring health belief model dimensions: a test of predictive value, internal consistency, and relationships among beliefs. Health Education Monographs 1977; 5: $215-229$.

10 Sackett DL et al. Randomized clinical trial of strategies for improving medication compliance in primary hypertension. The Lancet 1975; 1: 7918 - 1207.

11 Bowen RG, Rich R, Schlotfeldt RM. Effects of organized instruction for patients with the diagnosis of diabetes mellitus. Nurs Res 1961; 10: $151-159$

12 Hecht AB. Improving medication compliance by teaching outpatients. Nurs Forum 1974; 13: $112-129$.

13 Haynes RB, Taylor DW, Sackett DL. Compliance in Health Care. Johns Hopkins University Press, Baltimore, 1977.

14 Arnhold RG et al. Patients and prescriptions comprehension and compliance with medical instructions in a suburban pediatric practice. Pediatrics 1990; 9: 648-651.

15 Lindstrom CJ. No shows: a problem in health care. Nurs Outlook 1975; 23: $755-759$.

16 Bracken MB. The Jamaican family planning programme: Clinic services and social support as factors in dropping out. Int $J$ Health Educ 1977; 20: 126 - 135.

17 Rodriguez GP, Garber SC. Prospective study of pressure ulcer risk in spinal cord injury patients. Paraplegia 1994; 32: $150-158$.

18 Wallston KA, Wallston BS, DeVellis R. Development of the multidimensional health locus of control (MHLC) scales. Health Education Monographs 1978; 6: $160-170$.

19 Waites KB et al. Compliance with annual urologic evaluations and preservation of renal function in persons with spinal cord injury. J Spinal Cord Med 1995; 18: 251-254. 